\title{
ОСОБЕННОСТИ СЕЙСМИЧЕСКОЙ АКТИВИЗАЦИИ АВАЧИНСКОГО ВУЛКАНА В КОНЦЕ 2019 г.
}

\author{
(С) 2021 г. П. П. Фирстов ${ }^{1}$, А. А. Шакирова ${ }^{1, *}$, А. П. Максимов ${ }^{2}$, Е. В. Черных ${ }^{2}$ \\ Представлено академиком РАН Е.И. Гордеевым 05.11.2020 г. \\ Поступило 05.11.2020 г. \\ После доработки 15.01.2021 г. \\ Принято к публикации 15.01.2021 г.
}

\begin{abstract}
Сейсмическая активизация вулкана Авачинский наблюдалась с конца октября до конца декабря 2019 г., когда в его постройке произошло 6 роевых последовательностей вулканических землетрясений различных типов. В роевых последовательностях были выделены 15 плоско-ориентированных кластеров и определены характеристики их сейсмогенных площадок. Комплексный анализ сейсмических событий указывает на то, что активизация Авачинского вулкана в конце 2019 г. возникла в результате взаимодействия метеорных вод с магматическими телами в теле конуса, возникших в результате эффузивного извержения в 1991 г.
\end{abstract}

\begin{abstract}
Ключевые слова: сейсмическая активизация, вулканические землетрясения, плоско-ориентированные кластеры, гидротермальная активность
\end{abstract}

DOI: $10.31857 / \mathrm{S} 268673972104006 \mathrm{X}$

Вулкан Авачинский ${ }^{1}$ (высота 2751 м) ${ }^{2}$ на полуострове Камчатка (рис. 1) морфологически относится к типу Сомма-Везувий. Голоценовый вулкан Молодой конус располагается в кратере позднеплейстоценового вулкана Палео-Авача, с которым и связана современная активность. С 1737 г. по настоящее время произошло 15 извержений, различающихся по характеру и интенсивности $[1,2]$. После эксплозивного извержения субплинианского типа в 1945 г. на вулкане образовался кратер диаметром $\sim 250$ м и глубиной 170 м. Извержение, произошедшее в январе 1991 г., носило эффузивный характер и результатами его явились лавовая пробка в кратере (объемом $V=$ $\left.=8.3 \times 10^{6} \mathrm{M}^{3}\right)$ и лавовый поток на склоне вулкана $\left(V=4.4 \times 10^{6} \mathrm{M}^{3}\right)[1]$.

Следующее извержение, в виде слабой газовой эксплозии с выбросом пепла и некрупных глыб, произошло 05.10.2001 г. При этом образовалась тре-

\footnotetext{
${ }_{1}^{1}$ http://geoportal.kscnet.ru/volcanoes/volc?name=Avachinsky

2 Здесь и далее отчеты высот приводятся от уровня моря.
}

\footnotetext{
${ }^{1}$ Камчатский филиал Федерального исследовательского центра "Геофизическая служба Российской академии наук”, Петропавловск-Камчатский, Россия

${ }^{2}$ Институт вулканологии и сейсмологии Дальневосточного отделения Российской академии наук, Петропавловск-Камчатский, Россия

*E-mail:shaki@emsd.ru
}

щина/ров, рассекшая лавовую “пробку” в С3-ЮВ направлении с азимутом $325^{\circ}$. В обоих случаях перед извержениями в постройке вулкана регистрировались вулканические землетрясения (В3) с энергетическим классом $K<6.6(K=\lg E$, Дж) [4].

Микросейсмичность района Авачинского вулкана, в основном, контролируется 4 радиотелеметрическими сейсмическими станциями (РТСС) Камчатского филиала Федерального исследовательского центра "Единая геофизическая служба РАН”, расположенными на расстояниях от 2.4 до 6 км от кратера (рис. 1). Однако землетрясения с $K \geq 3.7$ регистрировались РТСС, расположенными на более удаленных расстояниях. Сеть РТСС позволяет определять координаты В3 в районе вулкана с энергетическим классом $K \geq 1.5$ $(K=\lg E$, Дж). Для вычисления координат очагов использовалась одномерная скоростная модель с возможностью поиска решений положений гипоцентров выше уровня моря [4]. Анализировались землетрясения, опубликованные в служебной базе данных КФ ФИЦ ЕГС РАН (http://www.emsd.ru/ts/). Обработка землетрясений и вычисление их параметров осуществлялись с помощью интерактивной программы DIMAS [5].

С 29 октября по 23 декабря 2019 г. в районе постройки вулкана Авачинский регистрировались рои В3 различных типов. В последний раз подобная сейсмичность наблюдалась в октябре-ноябре 2005 г. Всего было зарегистрировано 120 В3 с $K=1.2-6.6$ и диапазоном глубин от 2620 до -2040 м, 


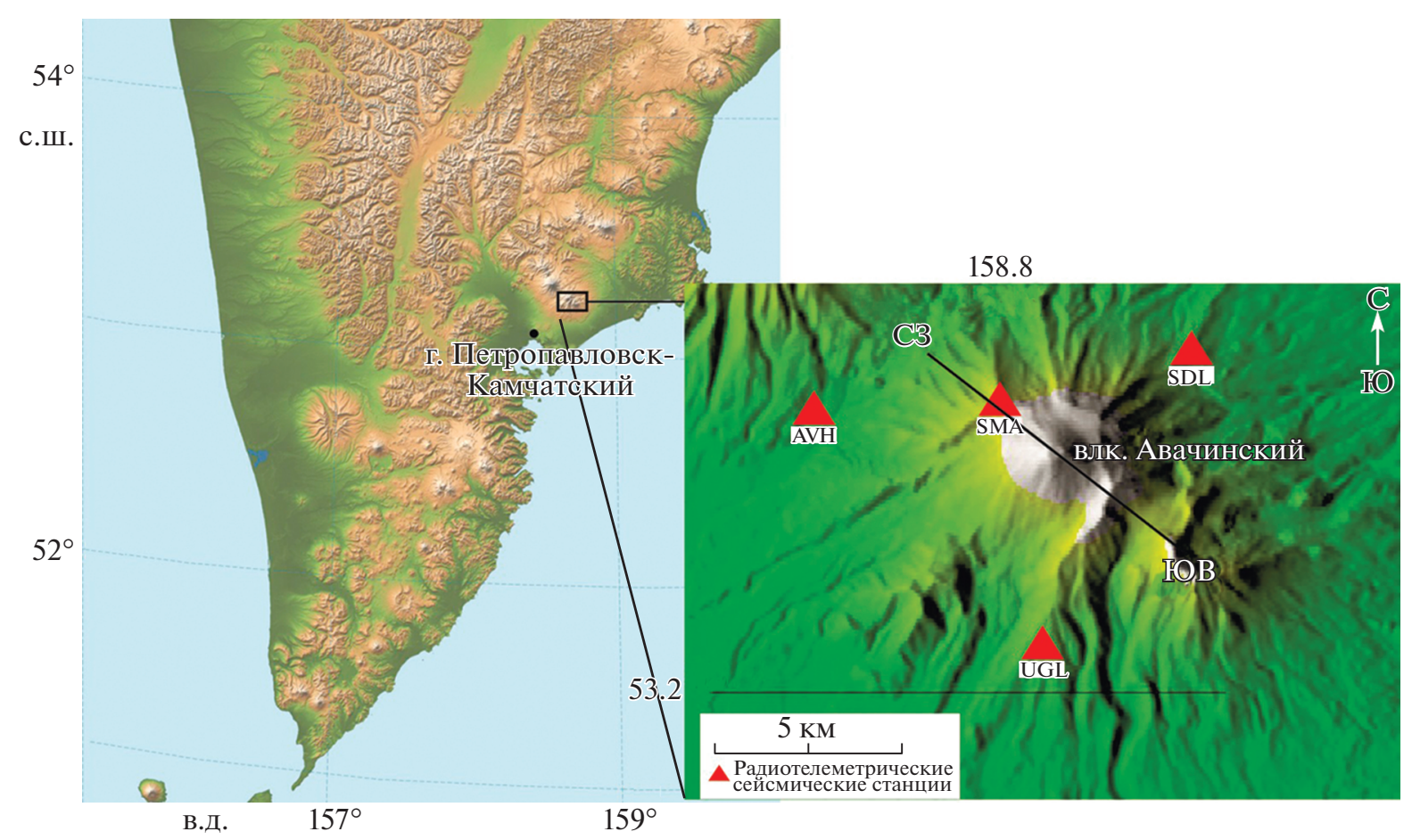

Рис. 1. Расположение вулкана Авачинский на Камчатке и радиотелеметрические сейсмические станции в его окрестности. Название PTCC: AVH - Авача, SMA - Сомма, SDL - Седловина, UDL - Угловая.

причем землетрясений с очагами ниже уровня моря было всего 5.

В работе [6] на основании определенных критериев разработана методика выделения в потоке В3 плоско-ориентированных кластеров (ПОК). В сейсмической активизации вулкана Авачинский были выделены ПОК и определены характеристики сейсмогенных площадок в интерактивной программе FracDigger (№ 2016616880)3․ Выделение ПОК происходило на основании следующих критериев: 1) временное ограничение событий менее суток; 2) разброс гипоцентров землетрясений в горизонтальной плоскости $\leq 6$ км; 3) их удаление от плоскости сейсмогенной площадки $\leq 200$ м; 4) количество землетрясений в кластере $\geq 6$.

На основании общепринятой классификации [7] разделение В3 осуществлялось по записям на PTCC SMA с использованием волновых форм и спектрального состава. Волновые формы приведены на левых панелях рис. 2, их спектральный состав - на правых.

Вулкано-тектонические землетрясения (ВТЗ), обусловленные хрупким разрушением геосреды, имели четкие вступления Р и $\mathrm{S}$-волн и $t_{\mathrm{s}}-t_{\mathrm{p}} \approx 0.8 \mathrm{c}$. На кривой спектральной плотности мощности

\footnotetext{
${ }^{3}$ П.А. Кирюхин, А.В. Кирюхин Frac-Digger. Свидетельство о государственной регистрации программы для ЭВМ № 2016612168 от 21.06.2016.
}

(СПМ) выделяются три спектральных максимума 10,12 и 15 Гц (рис. 2).

Гибридные землетрясения (ГЗ) имели четкие вступления с $t_{\mathrm{s}}-t_{\mathrm{p}} \approx 0.9 \mathrm{c}$, и наблюдалась запись хорошо выраженных кода-волн с более низкими частотами. На кривой СПМ выделяются два спектральных максимума -2.5 и 5.5 Гц (рис. 2). Механизм ГЗ принято связывать с процессом хрупкого разрушения геосреды с образованием трещины и дальнейшего еe заполнения магмой/флюидом [8].

Для длиннопериодных землетрясений (ДЗ) характерны нечеткие вступления $\mathrm{P}$ и $\mathrm{S}$-волн и более низкая частота относительно предшествующих типов, с двумя спектральными максимумами 1.5 и 4.0 Гц на СПМ (рис. 2). Принято считать, что механизм Д3 связан с разрушением геосреды с низкой плотностью или заполнением трещины магмой/флюидом. Д3 часто наблюдались перед извержениями.

Особые землетрясения (О3) с $K=1.9-4.2$ имели волновую форму, отличную от других В3. Они имели сравнительно короткую запись с резким вступлением Р-волны и $t_{\mathrm{s}}-t_{\mathrm{p}} \approx 0.5 \mathrm{c}$, при более низкой частоте в начальной части записи по сравнению с кода-волнами (рис. 2, верхняя панель). По волновым формам и частотному спектру О3 напоминали основную фазу (main phase) особых (special-type) землетрясений, зарегистрированных во время слабой активизации вулкана Иво-Дзи- 

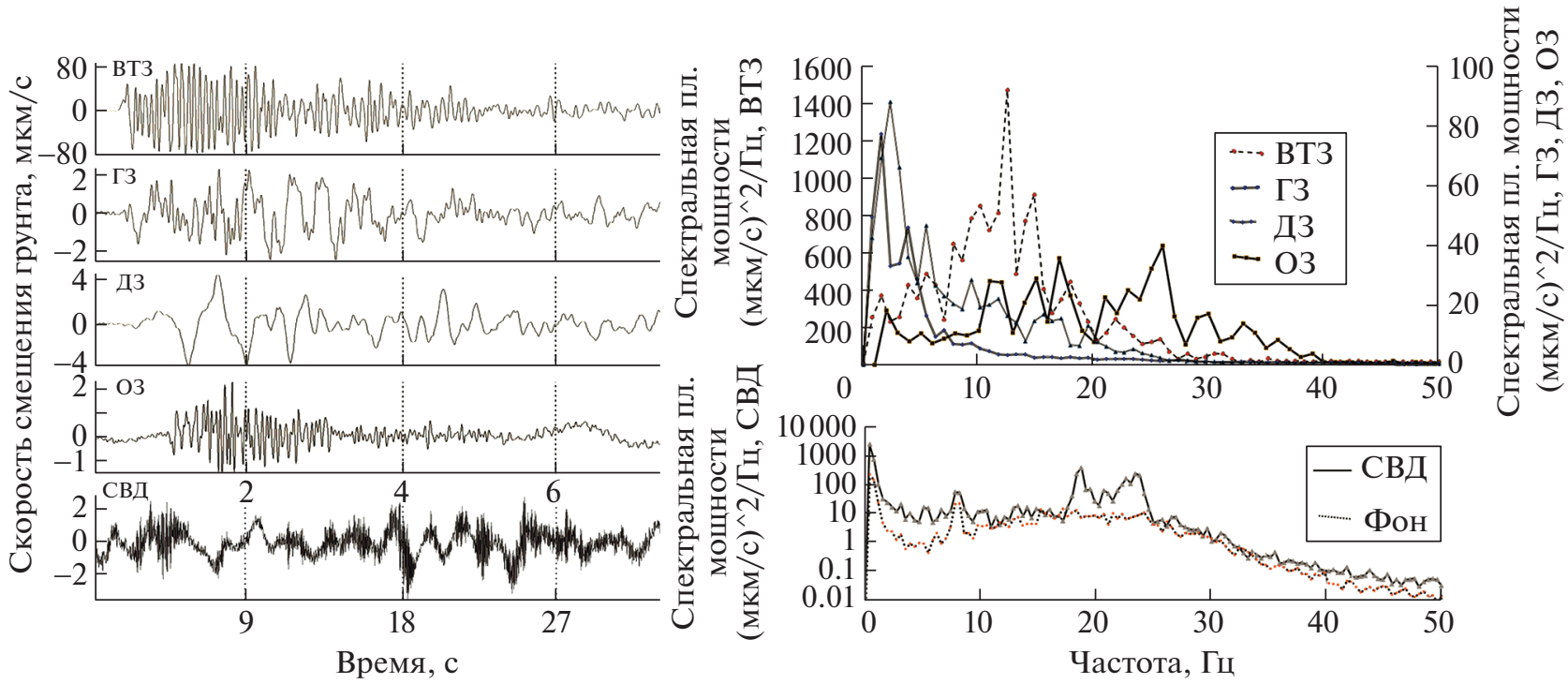

Рис. 2. Волновые формы землетрясений, зарегистрированные вертикальной компонентой на PTCC SMA (SHZ) во время активизации вулкана Авачинский в октябре-декабре 2019 г., и их спектральная плотность мощности: ВТ3 9.12.2019 г. в 14:54 с $K \mathrm{~s}=6.6, \mathrm{H}=-1.42$ км; ГЗ -10.12 .2012 г. в 23:03 с $K \mathrm{~s}=3.5, \mathrm{H}=1.8$ км; Д3 -18.11 .2019 г. в 16:01 с $K \mathrm{~s}=3.9, \mathrm{H}=1.8$ км; О3 $\times 3-5.11 .2019$ г. в $11: 46$ с $K \mathrm{~s}=3.6, \mathrm{H}=1.8$ км; СВД -26.12 .2019 г. в 08:49.
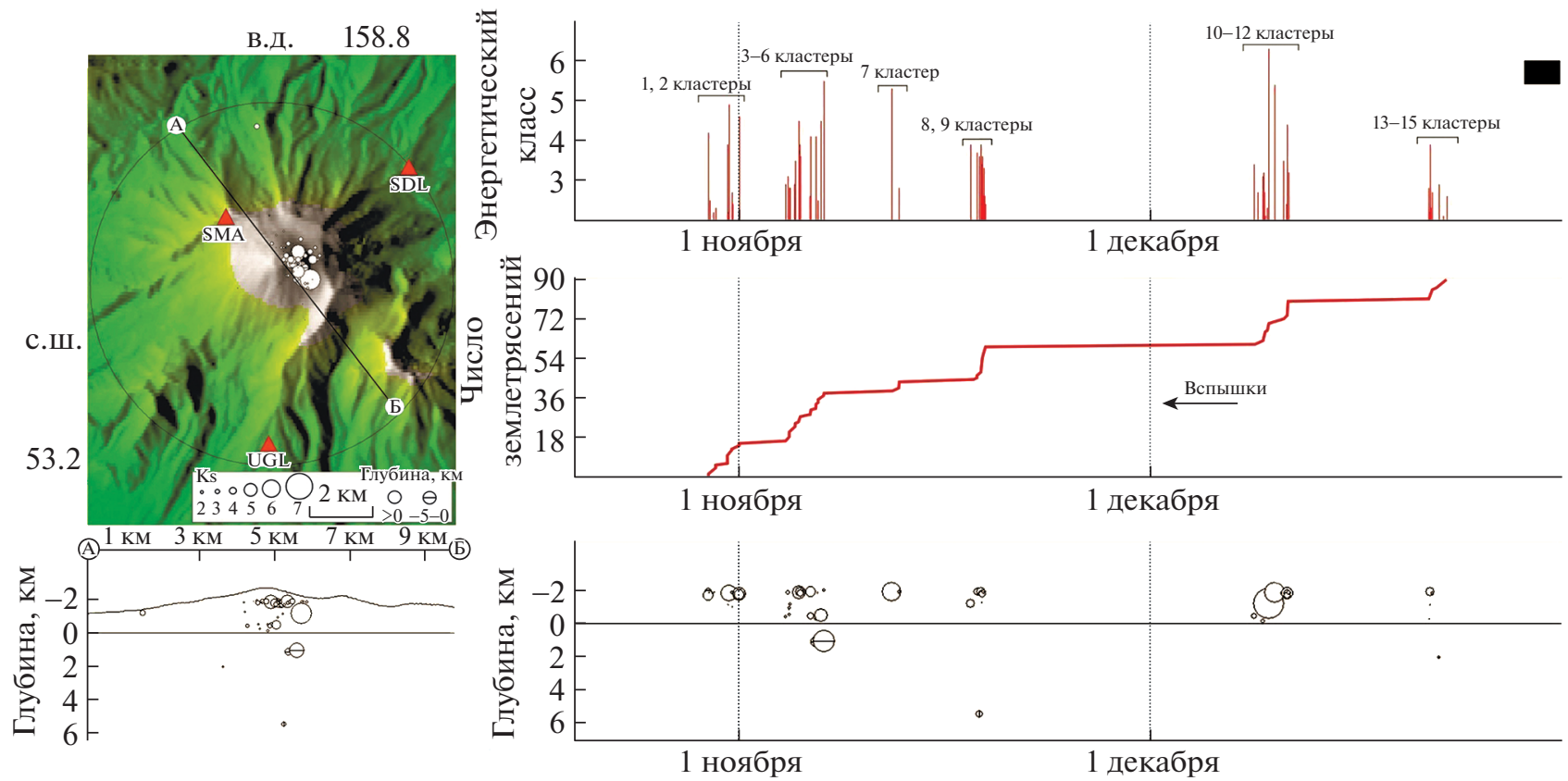

Рис. 3. Карта эпицентров землетрясений, произошедших в постройке вулкана Авачинский в октябре-декабре 2019 г., и проекция гипоцентров на вертикальную плоскость по линии А-Б (левая панель); распределение во времени энергетического класса $(K)$, кумулятивная кривая числа землетрясений, глубины гипоцентров землетрясений (правая панель). Черным прямоугольником выделен период СВД.

ма, Япония [9]. На кривой СПМ выделяются 5 спектральных максимумов: 2, 11-12, 15, 17 и 26 Гц (рис. 2, верхняя панель).

Кривые СПМ достаточно убедительно свидетельствуют о различии спектральных составов для выделенных типов В3.
Сейсмическая активизация закончилась слабым высокочастотным спазматическим вулканическим дрожанием (СВД), которое регистрировалось с 04 : 00 25.12. до 11 : 00 26.12.2019 г. На кривых СПМ выделяются два спектральных максимума: 19, 23.5 Гц (рис. 2, нижняя, правая панель), кото- 

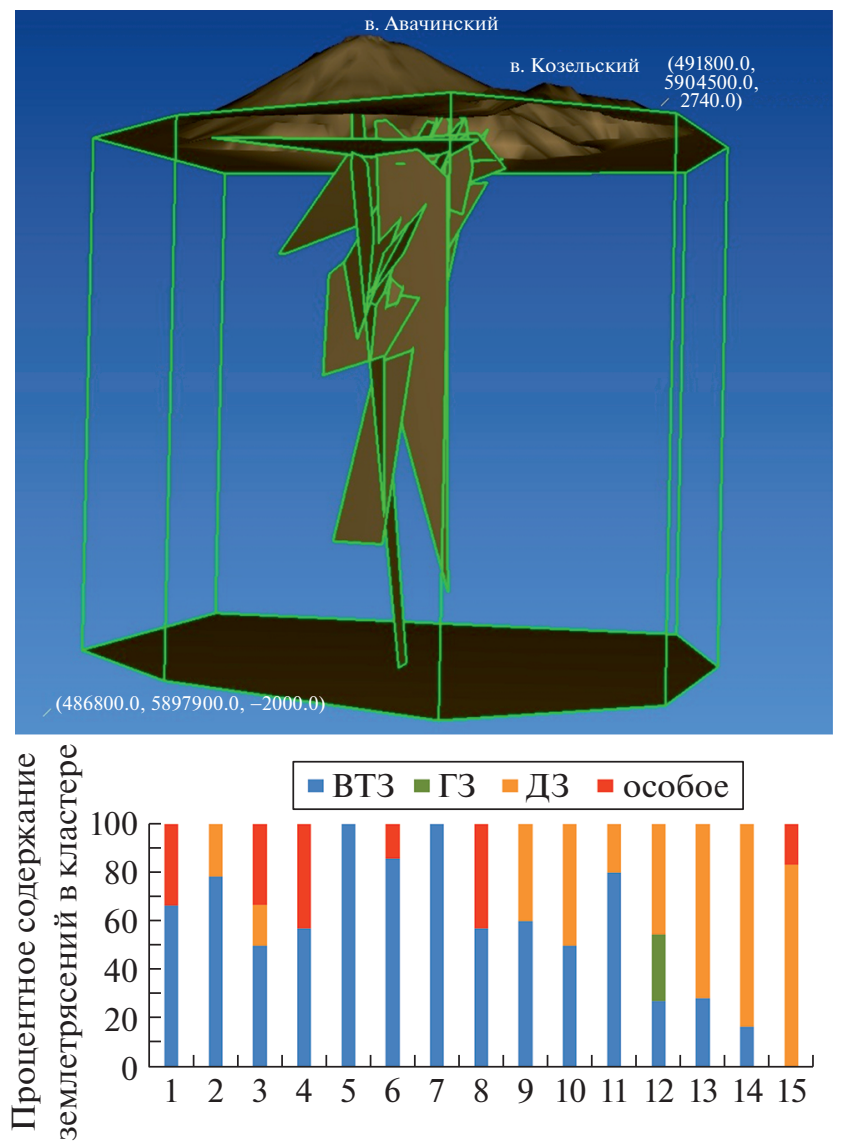

Рис. 4. 3D-визуализация плоско-ориентированных кластеров В3, выделенных в период октябрь-декабрь 2019 г., с верхней плоскостью на высоте 2000 м, а нижней -2000 м (верхняя панель). График процентного содержания В3 в кластерах (нижняя панель).

рые близки к высокочастотным максимумам О3. Так как в этот период отмечалось значительное усиление фумарольной активности, то можно предположить, что СВД возникло в результате движения флюида по проницаемой зоне, образовавшейся в результате сейсмической активизации.

На временном распределении землетрясений и на кумулятивной кривой их количества (рис. 3, правые панели) выделяются шесть роевых последовательностей В3 с $1.4<K<6.6$. Глубины основной массы очагов располагались на уровне $0<h<$ $<2$ км и тяготели к двум горизонтам $\sim 0.5$ и $\sim 1.8 \mathrm{KM}$, а их эпицентры были сосредоточены в C-CB-секторе конуса вулкана (рис. 3 , левые панели).

В рамках роевых последовательностей выделились 15 ПОК с центрами на глубинах от 300 до 1840 м (рис. 4, верхняя панель, табл. 1). В основном, кластеры имели субвертикальное расположение с углами падения от $59^{\circ}$ до $84^{\circ}$, но кластеры
№ $1,8,12$ - субгоризонтальное, с центром на высоте 1800 м (см. табл. 1).

Рассматривалось процентное содержание типов В3 в ПОК (рис. 4, нижняя панель). В начале активизации преобладали ВТ3, а в 4 последних кластерах процент ВТЗ резко снизился. Обратная картина относится к ДЗ, наибольшее число которых регистрировалось в конце активизации. ГЗ были зарегистрированы только в кластере № 12, в то время как О3 регистрировались в первой половине активизации.

Почти все В3 были сосредоточены в постройке Молодого конуса. Согласно геофизическим данным, периферический магматический очаг располагается на глубине от 0 до -2 км [10] или на глубинах ниже -2 км [11], что указывает на отсутствие связи активизации с процессами в вулканическом очаге.

Аналогичные сейсмические активизации происходили в периоды, в которых прослеживается сезонная закономерность: февраль-апрель 1996 г., конец августа-октябрь 2001 г., октябрь-ноябрь 2005 г. [4]. Она указывает на связь активизаций с повышенной обводненностью конуса за счет количества метеорных осадков осенью и таяния снежно-ледового покрова весной. Молодой конус сложен толщей рыхлых вулканогенных отложений с отдельными прослоями лав и относительно свободно проницаем для метеорных вод.

Разнообразие типов В3 указывает на несколько механизмов их возникновения, роль которых изменялась в течение сейсмической активизации. Она началась с формирования горизонтального ПОК на высоте $\sim 1800$ м, который на две трети был представлен ВТЗ и на треть ОЗ. На этом же уровне происходили события в горизонтальных кластерах № 8, 12. Причем доля ВТЗ в них снизилась до половины и менее трети соответственно. События этих ПОК фиксируют границу субгоризонтального горячего магматического тела и отражают его реакцию на контакт с холодными метеорными водами, что приводит к взрывному кипению с образованием трещин и возникновению О3.

Субвертикальные ПОК № 5, 7, представленные только ВТЗ, имели близкие углы падения $\left(75^{\circ}-80^{\circ}\right)$ и азимут простирания С3-ЮВ, что может свидетельствовать о субвертикальном магматическом теле, испытывающие контакт с метеорными водами. Причем 8 из 12 субвертикальных кластеров имели близкий азимут простирания. Таким телом могла быть дайка - канал поступления магмы во время извержения 1991 г., совпадающий с азимутом трещины/рва в кратере - peзультатом извержения 1991 г.

Если в первой половине периода активизации преобладали ВТЗ и существенную долю составляли О3, то затем роль ВТЗ постепенно снижалась, ОЗ практически исчезли, и стали преобладать ДЗ. 
Таблица 1. Геометрия плоско-ориентированных кластеров вулканических землетрясений вулкана Авачинский в период с 29.10.2019 по 22.12.2019 г.

\begin{tabular}{c|c|c|r|c|c|c|c|c|c|c}
\hline №№ & Дата & $\begin{array}{c}\text { Угол } \\
\text { падения }\end{array}$ & $\begin{array}{c}\text { Азимут } \\
\text { падения }\end{array}$ & $\mathrm{X}, \mathrm{м}$ & $\mathrm{Y}, \mathrm{M}$ & $\mathrm{Z}, \mathrm{M}$ & $K$ & $n$ & $S$, км$^{2}$ & $\lambda, \%$ \\
\hline 1 & 29.10 .19 & 1.6 & 110.5 & 489188 & 5900238 & 1840 & 4.2 & 6 & 2.0 & 67 \\
2 & 31.10 .19 & 66.6 & 262.0 & 489265 & 5900604 & 1510 & 4.6 & 14 & 1.7 & 79 \\
3 & 04.11 .19 & 81.4 & 72.9 & 489515 & 5900534 & 1650 & 3.5 & 6 & 0.7 & 50 \\
4 & 04.11 .19 & 57.9 & 288.2 & 489328 & 5900775 & 1290 & 4.5 & 7 & 0.9 & 57 \\
5 & 06.11 .19 & 82.7 & 242.5 & 489291 & 5900574 & 1410 & 4.1 & 6 & 0.5 & 100 \\
6 & 06.11 .19 & 81.7 & 69.3 & 489262 & 5900434 & 810 & 5.5 & 7 & 2.9 & 86 \\
7 & 12.11 .19 & 73.6 & 257.9 & 489179 & 5900771 & 1640 & 5.3 & 6 & 1.2 & 100 \\
8 & 17.11 .19 & 10.9 & 20.0 & 489197 & 5901039 & 1810 & 3.9 & 14 & 2.9 & 50 \\
9 & 18.11 .19 & 83.9 & 104.9 & 488982 & 5900870 & 780 & 3.6 & 10 & 2.7 & 67 \\
10 & 08.12 .19 & 65.6 & 246.1 & 489146 & 5900960 & 990 & 3.4 & 8 & 2.1 & 50 \\
11 & 09.12 .19 & 81.6 & 251.8 & 489154 & 5900904 & 300 & 6.6 & 6 & 2.0 & 80 \\
12 & 10.12 .09 & 6.0 & 221.8 & 489353 & 5900585 & 1810 & 4.4 & 11 & 0.6 & 27 \\
13 & 21.12 .19 & 71.9 & 239.3 & 488828 & 5901139 & 1330 & 3.9 & 7 & 2.6 & 29 \\
14 & 22.12 .19 & 59.4 & 348.1 & 489092 & 5900708 & 500 & 2.9 & 6 & 5.2 & 17 \\
15 & 22.12 .19 & 59.9 & 203.5 & 489338 & 5900679 & 1040 & 3.1 & 6 & 3.8 & 0 \\
\hline
\end{tabular}

Примечание. X, Y, Z - координаты центров кластеров (система координат UTMWGC-84); $K$ - максимальный энергетический класс в кластере; $n, S$ - число землетрясений в кластере и его площадь; $\lambda$ - процентное содержание ВТЗ в кластере. Выделены горизонтальные кластеры.

Это может свидетельствовать о том, что процесс хрупкого разрушения уступил главную роль процессу, обусловленному взрывным вскипанием водного флюида в пределах лавово-пирокластической толщи конуса. Наличие Д3, О3 и ГЗ говорит о различных механизмах их генерации и различной роли процессов хрупкого разрушения. Активизация закончилась генерацией СВД 25 и 26 декабря, обусловленного интенсивным движением флюида.

Детальный анализ сейсмических событий с применением методики выделения ПОК указывает на то, что активизация Авачинского вулкана в конце 2019 г. возникла в результате взаимодействия метеорных вод с магматическими телами в конусе вулкана.

\section{ИСТОЧНИКИ ФИНАНСИРОВАНИЯ}

Работа выполнялась в рамках государственного задания по проектам AAAA-A19-119031590060-3, AAAA-A17-117050210046-7 и с использованием данных, полученных на уникальной научной установке “Сейсмоинфразвуковой комплекс мониторинга арктической криолитозоны и комплекс непрерывного сейсмического мониторинга Российской Федерации, сопредельных территорий и мира".

\section{СПИСОК ЛИТЕРАТУРЫ}

1. Мелекесцев И.В., Брайцева О.А., Двигало В.Н. и др. Исторические извержения Авачинского вулкана на Камчатке (попытка современной интерпретации и классификации для долгосрочного прогноза типа параметров бедующих извержений) Ч. II (1926-1991 гг.) // Вулканология и сейсмология. 1994. № 2. C. $3-23$.

2. Мелекесиев И.В., Селиверстов Н.И., Сенюков С.Л. Информационное сообщение об активизации в октябре 2001 г. // Вулканология и сейсмология. 2002. № 2. С. $79-80$.

3. Дубровская И.К., Черкашин Р.И., Чирков С.А. Тепловой (ThermaCam SC 640) и сейсмический режим вулкана Авачинский в 2000-2018 гг. // Мат. конф. "Современный вулканизм и связанные с ним процессы”, 28-29 марта 2019 г. - ПетропавловскКамчатский: ИВиС ДВО РАН, 2019. С. 19-21.

4. Сенюков С.Л., Нуждина И.Н., Дрознина С.Я. и др. Сейсмичность Авачинского вулкана в 19942005 гг. // Мат. конф. “Геофизический мониторинг Камчатки”, Петропавловск-Камчатский, 1718 января 2006 г. Петропавловск-Камчатский: ГС РАН, 2006. С. 101-105.

5. Дрознин Д.В., Дрознина С.Я. Интерактивная программа обработки сейсмических сигналов DIMAS // Сейсмические приборы. 2010. Т. 46. № 3. С. 22-34. 
6. Кирюхин А.В., Федотов С.А., Кирюхин П.А. Геохимическая интерпретация локальной сейсмичности, связанной с извержениями и активизацией вулканов Толбачик, Корякский и Авачинский, Камчатка в 2008-2012 гг. // Вулканология и сейсмология. 2016. № 5. С. 3-20.

7. Zobin V.M. Introduction to Volcanic Seismology. Third edition. Elsevier: Amsterdam. 2017. 559 p.

8. Гордеев Е.И., Сенюков С.Л. Сейсмическая активизация вулкана Корякский в 1994 г.: гибридные сейсмические события и их применение для оценки вулканической опасности // Вулканология и сейсмология. 1998. № 4-5. С. 112-126.
9. Uchida N., Sakai T. Analysis of Peculiar Volcanic Earthquakes at Satsuma-Iojima Volcano // Earth Planets Space. 2002. V. 54. P. 197-209.

10. Мороз Ю.Ф., Гонтовая Л.И. Глубинное строение района Авачинско-Корякской группы вулканов на Камчатке // Вулканология и сейсмология. 2003. № 4. C. 3-10.

11. Bushenkova N., Koulakov I., Senyukov S., et al. Tomographic Images of Magma Chambers Beneath the Avacha and Koryaksky Volcanoes in Kamchatka // Journal of Geographical Research: Solid Earth. 2019. Iss. 9. V. 124. P. 9694-9713. https://doi.org/10.1029/2019JB017952

\title{
FEATURES OF THE SEISMIC ACTIVATION OF AVACHINSKY VOLCANO AT THE END OF 2019
}

\author{
P. P. Firstov ${ }^{a}$, A. A. Shakirova ${ }^{a, \#}$, A. P. Maksimov ${ }^{b}$, and E. V. Chernykh ${ }^{b}$ \\ ${ }^{a}$ Kamchatka Branch of the Federal Research Center "Geophysical Service of the Russian Academy of Sciences", \\ Petropavlovsk-Kamchatskiy, Russian Federation \\ ${ }^{b}$ Institute of Volcanology and Seismology, Far East Branch, Russian Academy of Sciences, \\ Petropavlovsk-Kamchatskiy, Russian Federation \\ ${ }^{\#}$ E-mail: shaki@emsd.ru
}

Presented by Academician of the RAS E.I. Gordeev November 05, 2020

\begin{abstract}
Seismic activation of Avachinsky volcano was observed from late October to late December 2019, when 6 swarm sequences of volcanic earthquakes of various types occurred in its construction. In the swarm sequences, 15 plane-oriented clusters were identified and the characteristics of their seismogenic areas were determined. A comprehensive analysis of seismic events indicates that the activation of Avachinsky volcano at the end of 2019 arose because of the interaction of meteoric waters with magmatic bodies in the body of the cone, which arose during an effusive eruption in 1991.
\end{abstract}

Keywords: seismic activation, volcanic earthquakes, plane-oriented clusters, hydrothermal activity 